\title{
Economic Forecasting and the Role of the Economist
}

\author{
Stephen Kirchner
}

$\mathrm{F}$ INANCIAL market economists devote considerable time and effort to forecasting economic data. Yet there have been few systematic attempts to test the efficiency of these forecasts in an Australian context.

An obvious question is whether these forecasts significantly outperform a simple moving average model. For economists to be able to justify the effort they put into forecasting, their average forecast error should be significantly narrower than that generated by a naive model.

Standard \& Poor's MMS has surveyed economists' expectations for key Australian data releases for over ten years. While the resulting market medians are the forecast of only the 'middle' economist, the academic literature suggests that individual economists cannot outperform market medians over sustained periods of time. Taking the market median as the 'representative' economist is therefore likely to strengthen the overall forecast accuracy of market economists as a group relative to what any individual forecaster is likely to achieve.

Table 1 sets out the average forecast error made by the median economist for each quarterly GDP and CPI release since the June quarter 1985. This is compared with the average forecast error generated by a simple four-period moving average model. The model takes the average of the previous four quarters' GDP or CPI growth as the forecast for the subsequent quarter. The moving average model is applied to the data as originally reported. These are the same data as those available to economists at the time they made their forecast.

The table shows that the average GDP forecast error of the median economist is only 0.15 percentage points less than that for the naive model. Taking out the more extreme errors by using the median instead of the average error still sees economists outperform the naive model by only 0.19 percentage points. Similarly, the average CPI forecast error of the median economist is only 0.25 percentage points less than that of the naive model. With the CPI, we are probably more justified in using the median error, given some of the large forecast errors made by both economists and the naive model due to the rapid structural break in inflation that occurred in the early 1990s. In this case, the economist does only 0.15 percentage points better than the naive model. While this is a potentially significant difference in forecast accuracy in today's low inflation environment, it is less significant for most of the period since 1985 . 


\section{Table 1}

Median economist vs naive model, June quarter 1985 to June quarter 1997

\begin{tabular}{lccc}
\hline & Median economist & Naive model & Difference \\
\hline GDP* (\% points) & & & \\
Average absolute error & 0.54 & 0.68 & 0.15 \\
Median absolute error & 0.43 & 0.62 & 0.19 \\
Maximum error & 2.60 & 1.97 & \\
& & & \\
CPI (\% points) & & & \\
Average absolute error & 0.23 & 0.48 & 0.25 \\
Median absolute error & 0.20 & 0.35 & 0.15 \\
Maximum error & 0.90 & 1.88 & \\
\hline
\end{tabular}

"GDP(I) to September quarter 1991. GDP(A) from December quarter 1991. As originally reported.

Sources: Standard \& Poor's MMS; Australian Bureau of Statistics (various years), Australian National Accounts: National Income, Expenditure and Product, Canberra (Cat. No. 5206.0).

These results are interesting, not least because the quarterly GDP and CPI releases are more amenable to forecasting than many other statistical releases. For example, many of the components of GDP are known with a reasonable degree of precision in advance of the release. Economists have a good idea as to the contribution to GDP from consumption, capital expenditure, net exports, and stocks on the expenditure side. On the income side, they have reasonable clues as to the wages, salaries and supplements component and the private gross operating surplus. Similarly, the CPI is based on the prices of a known basket of goods and services. Most of these prices are readily observable in the market place.

The median economist's forecasts are clearly an improvement on those generated by a naive model, but this is the least we should expect. The key question is whether this improvement adds value for market participants.

The debt and foreign exchange markets are usually quite tolerant of small differences between actual and expected outcomes in official data releases. The small difference in forecast accuracy between the median economist and the simple model suggests that market participants are unlikely to be significantly advantaged in taking a position based on the economist's forecast rather than the simple model. In the case of GDP releases, for example, the market is not much more likely to move on an outcome that is $\mathbf{0 . 6 8}$ percentage points higher or lower than expected than on an outcome 0.54 percentage points higher or lower than expected, all else being equal.

Another way of looking at the usefulness of economists' forecasts is to examine whether there is a relationship between the degree of consensus among economists and forecast accuracy. We might expect that where there is agreement about their forecasts, there is also an increase in forecast accuracy. The ure of market medians 
is based on a slightly different assumption, namely, that the forecast furthest away from the two extremes is most likely to be correct.

The range of market expectations provides a crude measure of consensus among economists about a given data release. Unfortunately, the original populations for the survey data cited above were not available to generate a more sophisticated measure of market consensus (for example, by taking the standard deviation of the forecasts for each release).

Table 2 reports correlation coefficients between the range of market expectations and subsequent forecast errors for each quarterly GDP and CPI release:

\section{Table 2}

Relationship between market consensus and forecast accuracy, June quarter 1985 to June quarter 1997

\begin{tabular}{ccc}
\hline & $G D P^{*}$ & $C P I$ \\
\hline Correlation coefficient & -0.03 & 0.07 \\
\hline
\end{tabular}

*Forecasts for GDP(I) to September quarter 1991. GDP(A) from December quarter 1991.

Sources: Standard \& Poor's MMS; Australian Bureau of Statistics (various years), Consumer Price Index, Canberra (Cat. No. 5204.0).

The close-to-zero coefficients show no relationship between the range of forecasts and subsequent forecast accuracy. Relative agreement among economists does not make their forecasts any better, but it does not make them any worse, as a market contrarian might argue.

Does this mean that economists should do away with point forecasting of official data? No, but it does suggest the need for more realistic expectations about what point forecasts can achieve. If an economy is as unpredictable as cconomists' forecast accuracy would suggest, then we should be less preoccupied with generating and acting on these forecasts. Instead, economists should work more with what they know rather than with what they don't. This means putting more effort into assessing data after they are released and also the underlying risks and trends for the market. This would arguably be a more efficient, and often far less embarrassing, use of economists' skills.

Apart from the usefulness of point forecasts, these results raise larger questions about the role of the economist. Given the limitations on economists' forecast accuracy, why do economists enjoy such a prominent role? An obvious answer is that economists provide useful explanations of economic and financial developments. This fits well with McCloskey's (1985) exposition of the rhetorical role performed by the economist. The economist as 'rhetor' is a good description of the 'talking head' role of contemporary financial economists, whose media appearances and presentations to external clients are a major part of their work.

The broader role of the economist is not so much to supply accurate point forecasts as to provide a useful and convenient framework for understanding 
current economic and financial developments. An understanding of the reasons behind a given outcome and its wider significance is probably more important than the ability to forecast this outcome with precision. This is a potentially valuable role, which economists are well equipped to perform, so long as these frameworks do not become simple cases of ex post rationalisation.

\section{Reference}

McCloskey, D. (1985), The Rhetoric of Economics, University of Wisconsin Press, Madison. 